\title{
Body mass index estimation and measurement by healthcare professionals
}

\author{
Tomás Ahern ${ }^{1 *}$, Kirsten Doherty ${ }^{2}$, Daniel Kapeluto ${ }^{3}$, Maeve Davis ${ }^{1}$, Una Mulholland ${ }^{4}$, \\ Edwina Rossiter ${ }^{4}$, Irene Gilroy ${ }^{2}$, Astrid Billfalk-Kelly ${ }^{1}$, Patricia FitzPatrick ${ }^{2}$, Leslie Daly ${ }^{2}$, \\ Cecily Kelleher ${ }^{2,5}$, Donal O'Shea ${ }^{1,5}$ \\ ${ }^{1}$ Department of Endocrinology, St. Vincent’s University Hospital, Dublin, Ireland; \\ *Corresponding Author: tomasbahern@physicians.ie \\ ${ }^{2}$ Department of Preventive Medicine and Health Promotion, St. Vincent’s University Hospital, Dublin, Ireland \\ ${ }^{3}$ Department of Family Medicine, Memorial University of Newfoundland, St. John's, Canada \\ ${ }^{4}$ Department of Nursing, Midwifery and Health Studies, School of Health \& Science, Dundalk Institute of Technology, Dundalk, \\ Ireland \\ ${ }^{5}$ Irish Health Research Board Centre for Food and Health, University College Dublin, Dublin, Ireland
}

Received 13 March 2012; revised 24 April 2012; accepted 16 May 2012

\section{ABSTRACT}

Background: Severe obesity has increased more than three-fold in prevalence over the past fifteen years in Europe and the United States. Correctly identifying severe obesity permits access to mortality-reducing interventions. We aimed to determine the accuracy of healthcare professionals (HCPs) in recognising severe obesity and the frequency of body mass index (BMI) assessment by HCPs. Methods: We performed two cross-sectional surveys: one of 206 HCPs in Ireland and Canada and another of 515 Irish hospital healthcare records. The first survey evaluated $B M I$ estimation from photographs and the second examined recording of weight and height during outpatient clinic visits. Results: HCPs underestimated the BMI of severely obese people by an average of $22 \%$ to $39 \%$. For a patient with a BMI of $52 \mathrm{~kg} / \mathrm{m}^{2}, 35.4 \%$ of family physicians appreciated that the patient was severely obese (BMI > $40 \mathrm{~kg} / \mathrm{m}^{2}$ ) compared with $81.0 \%$ of endocrinologists. During clinic visits only $18.1 \%(n=75), 1 \%(n=4)$ and $0 \%(n=0)$ of patients had their respective weights, heights and BMls recorded. Conclusions: HCPs frequently fail to recognise severe obesity from photographs and, in our centre, do not routinely record weight or height. Whether patient outcomes can be improved by measuring weight and height during every HCP encounter warrants further study.

Keywords: Severe Obesity; Body Mass Index; Healthcare Professionals

\section{INTRODUCTION}

The obesity epidemic continues to provide challenges to healthcare professionals (HCPs). American and European data suggest that the prevalence of obesity (body mass index [BMI] $>30 \mathrm{~kg} / \mathrm{m}^{2}$ ) has approximately doubled over the past fifteen years [1-5]. Over the same time period the prevalence of severe obesity (BMI $>40 \mathrm{~kg} / \mathrm{m}^{2}$ ) has increased three- to five-fold [6,7]. Obesity confers a $22 \%$ increase in overall mortality, a $48 \%$ increase in cardiovascular disease (CVD) mortality and a $7 \%$ increase in cancer mortality [8]. Moderate intentional weight loss brings about multiple health benefits including a $24 \%$ reduction in mortality at 8 years [9]. For people with severe obesity bariatric surgery brings about a $24 \%$ reduction in mortality at 11 years and gastric bypass surgery effects a $40 \%$ reduction in mortality at 7 years $[10,11]$.

In order to obtain benefit from such evidence based interventions, obese and severely obese people must be correctly identified in order to permit referral to appropriate HCPs who can provide these interventions. When recognised as obese, obese people receive higher levels of dietary counseling than people of a similar BMI who have not been recognised as obese [12-14]. The American Society for Metabolic and Bariatric Surgery recommends that bariatric surgery be considered only for those with severe obesity.

The accuracy of HCPs in recognising severe obesity is poorly studied. Obesity (non-severe) recognition rates range from 20\% - 65\% among physicians [12,13,15-17]. Data on the accuracy of other HCPs in identifying obesity is lacking. Similarly, there is a dearth of information on the accuracy of any HCP in recognising severe obesity [17].

We sought to determine 1) the accuracy of HCPs in identifying severe obesity by visual inspection and 2) the 
frequency of obesity screening in routine hospital practice. We hypothesised that HCPs frequently fail to recognise severe obesity and that clinician encounters rarely involve determination of BMI.

\section{METHODS}

\subsection{Survey of Healthcare Professionals' Estimation of BMI}

We performed a cross-sectional survey of healthcare professionals in Ireland and in Canada in 2009. All consultant endocrinologists in Ireland and all general practitioners in south-east county Dublin and north county Wicklow were invited to participate in this study. The names and addresses of the physicians were obtained from the 2009 Irish Medical Directory. Physiotherapists and dietitians attending either the 2009 annual meeting of either the Eastern branch of the Irish Society of Chartered Physiotherapists or a regional meeting of the Irish Nutrition and Dietetic Institute were also recruited into this study. The healthcare professionals working in Canada who were invited to participate were: endocrinologists listed under the College of Physicians and Surgeons of Newfoundland and Labrador; family doctors who were registered as members of the Newfoundland and Labrador chapter of the College of Family Physicians of Canada; dietitians registered in Newfoundland and Labrador; and physiotherapists registered with the Atlantic Provinces' Physiotherapy Associations.

We designed a questionnaire for this study, which consisted of 5 pairs of photographs. Each pair was made up of a front- and a side-on view of an obese person and the photographs in each pair were placed adjacent to each other. The photographs were full-length, did not include the face, and were taken using a digital camera at a distance of 2.5 meters (see Figures 1(a) and (b)). The order in which the pairs of photographs were seen was random and not related to body mass index (BMI). Research participants were asked to estimate, by visual inspection of the photographs, the BMI of each of the 5 people photographed. The photographs were of people attending a weight management clinic who were dressed in usual attire and who provided informed consent to the photographs being taken. Trained staff measured the height of all patients using a stadiometer (Seca, Hamburg, Germany) while the patient was standing erect without shoes. Weight was measured to $0.1 \mathrm{~kg}$ using a manually calibrated electronic scales (Seca, Hamburg, Germany) with the patients in normal clothes, but without shoes.

The questionnaire was printed and sent, together with an explanatory letter and a stamped addressed envelope, to the Irish endocrinologists, the Irish general practitioners and the Canadian healthcare professionals. High quality paper was used to make this printed version of the questionnaire and each of the 3 pages contained a maximum of four $11.5 \mathrm{~cm} \times 8 \mathrm{~cm}$ size photographs. The same questionnaire (containing the same photographs) was presented, in PowerPoint ${ }^{\circledR}$ format, during presentations by one of the senior authors (DO'S) to the Irish dietitians and to the Irish physiotherapists.

\subsection{Survey of Healthcare Records Documentation}

We performed a systematic survey of a stratified random sample of patient healthcare records. The healthcare records belonged to patients who had appointments to attend an out-patient clinic in an Irish university teaching hospital during the week of the $15^{\text {th }}$ to the $22^{\text {nd }}$ of February 2010. Before collecting the data, all clinics were categorised into one of three groups (high, medium or low) according to likelihood of the attending patients being weighed for medical, nutrition or drug calculation reasons. A random selection of clinics was taken from each group. Examples of high likelihood clinics included cardiology and gastroenterology while those viewed as low likelihood included dermatology and psychiatry. All healthcare records of patients due to attend the selected clinics were examined for the recording of height, weight, and waist circumference measurements during the clinic visit and during the preceding year. Actual measurements and clinic type were also noted. Healthcare record thickness was quantified using calibrated calipers (see Figure 2(b)). The healthcare records of patients who failed to attend their clinic appointment were examined for recording of measurements made during the preceding year. The availability of equipment for measuring height, weight and waist circumference at each selected clinic was noted.

Approval was obtained from the hospital's Clinical Audit Committee and the hospital's Medical Executive was informed of the intention to carry out this survey.

\subsection{Statistical Analyses}

Data were entered and analysed using Version 18 of the PASW Statistics software package (Chicago, IL, USA). Data are expressed as median (interquartile range) for continuous variables and as percentage (number) for dichotomous variables. The independent-samples KruskalWallis test was used to test for significant differences between groups in the estimated BMIs and the differences from actual BMIs. Chi-square tests were used to compare proportions between groups.

\section{RESULTS}

\subsection{Survey of Healthcare Professionals}

The response rates for the postal surveys were $46.0 \%$ 
and $40.0 \%$ for Irish and Canadian endocrinologists respectively and $22.6 \%$ and $10.6 \%$ for Irish and Canadian general practitioners respectively. The response rates for other Canadian HCPs were $17.7 \%$ for dietitians and 6.8\% for physiotherapists. All HCPs who attended the annual meetings completed the questionnaire (100\% response rate). Data were therefore available for 21 endocrinologists, 96 general practitioners (GPs), 50 dietitians and 39 physiotherapists (total $=206$ ).

On visual estimation HCPs underestimated the BMI of obese people by an average of between $9 \%$ to $39 \%$. Average underestimation was more marked for those with severe obesity (22\% to $39 \%$ ) compared to those with non-severe obesity ( $9 \%$ to $25 \%$ ). For the person with a

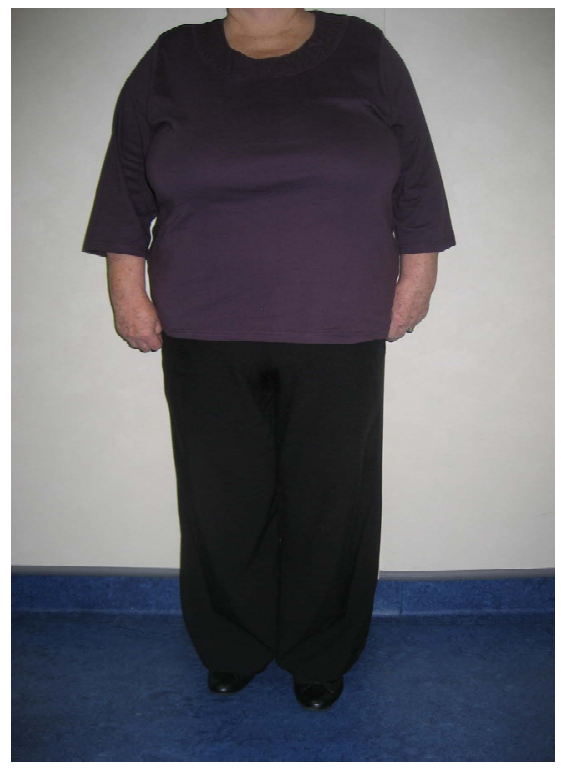

(a)

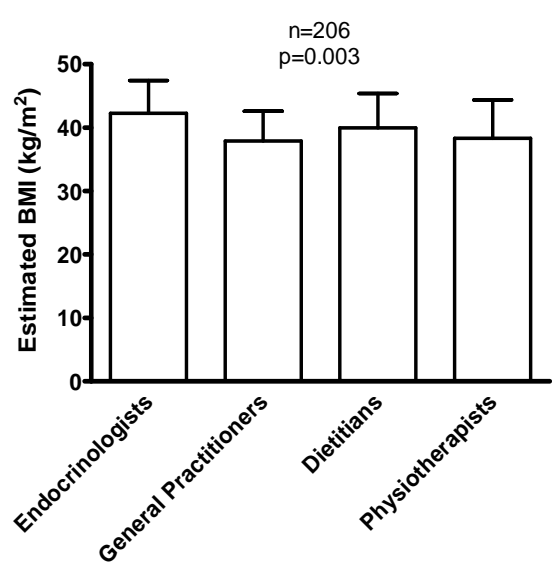

(c)
BMI of $52 \mathrm{~kg} / \mathrm{m}^{2}$, average BMI estimation for GPs was $38 \mathrm{~kg} / \mathrm{m}^{2}$ (35 - $40 \mathrm{~kg} / \mathrm{m}^{2}$ ) compared with the average consultant endocrinologist's estimation of $42 \mathrm{~kg} / \mathrm{m}^{2}$ (40 $45 \mathrm{~kg} / \mathrm{m}^{2}$ ) (Table 1(a) and Figure 1(c)). 35.4\% to $81.0 \%$ (47.6\% overall) of healthcare professionals failed to recognise that the same person (BMI $52 \mathrm{~kg} / \mathrm{m}^{2}$ ) was severely obese (BMI $>40 \mathrm{~kg} / \mathrm{m}^{2}$ ) (Table 1(b) and Figure 1(d)).

\subsection{Survey of Healthcare Records}

Five hundred and fifteen (515) healthcare records were identified from 26 clinics. This sample represented 20\% of clinics and $20 \%$ of patients due to attend all clinics. 100 patients did not attend their appointments during the

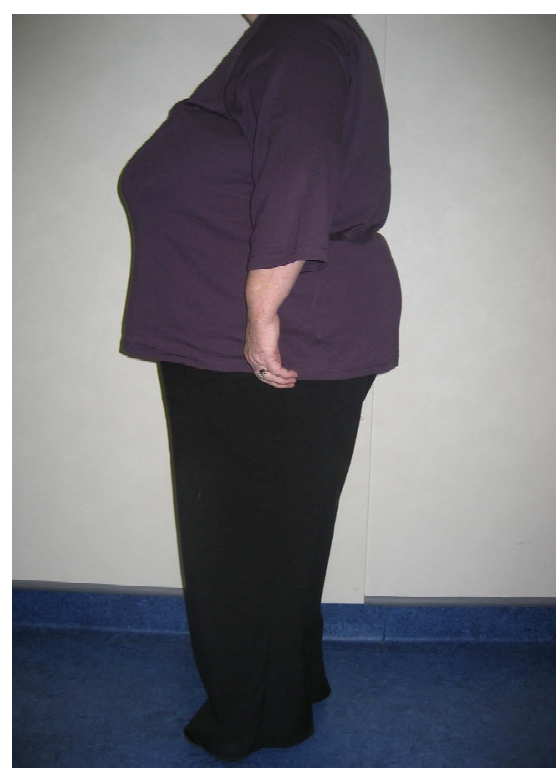

(b)

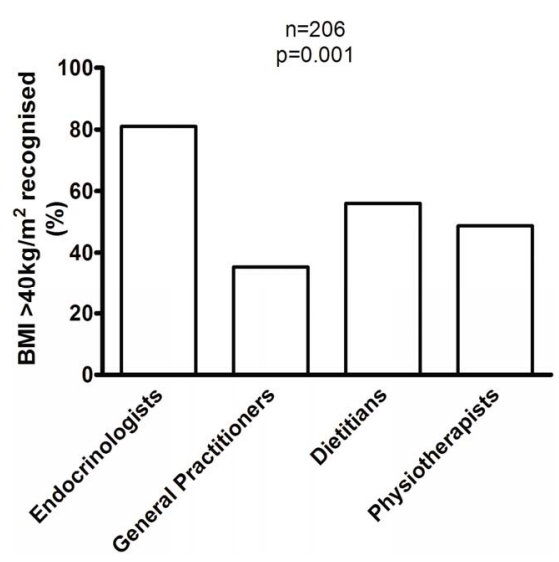

(d)

Figure 1. (a) and (b), Example of a pair of front- and side-on photographic views used of a person with a BMI of $52 \mathrm{~kg} / \mathrm{m}^{2}$. Research participants were asked to estimate BMI using these photographs; (c) BMIs estimated by healthcare professionals using the photographs in (a) and (b); (d) Proportion of healthcare professionals able to recognise that the photographed person had a BMI $>40 \mathrm{~kg} / \mathrm{m}^{2}$ (was severely obese). 
Table 1. (a) Estimated BMIs ( $\left.\mathrm{kg} / \mathrm{m}^{2}\right)$ for each of the images by each of the healthcare professional groups; (b) Proportion (\%) of each healthcare group that appreciated the correct class of obesity.

(a)

\begin{tabular}{|c|c|c|c|c|c|c|c|}
\hline \multirow{2}{*}{$\begin{array}{c}\text { Actual BMI } \\
\left(\mathrm{kg} / \mathrm{m}^{2}\right)\end{array}$} & \multicolumn{7}{|c|}{ Estimated BMI $\left(\mathrm{kg} / \mathrm{m}^{2}\right)$} \\
\hline & $\begin{array}{l}\text { Endos } \\
(\mathrm{n}=21)\end{array}$ & $\begin{array}{c}\text { GPs } \\
(\mathrm{n}=96)\end{array}$ & $\begin{array}{l}\text { Dietitians } \\
(\mathrm{n}=50)\end{array}$ & $\begin{array}{l}\text { Physios } \\
(\mathrm{n}=39)\end{array}$ & $\begin{array}{c}\text { All } \\
(\mathrm{n}=206)\end{array}$ & p Value ${ }^{a}$ & p Value $^{b}$ \\
\hline 32 & $31(29-34)$ & $29(28-31)$ & $29(27-31)$ & $28(26-28)$ & $29(27-31)$ & $<0.001$ & $<0.001$ \\
\hline 40 & $32(30-35)$ & $30(30-33)$ & $30(29-32)$ & $30(27-32)$ & $30(29-33)$ & 0.002 & $<0.001$ \\
\hline 51 & $40(38-49)$ & $40(35-42)$ & $40(37-45)$ & $38(34-40)$ & $40(35-42)$ & 0.044 & $<0.001$ \\
\hline 52 & $42(40-45)$ & $38(35-40)$ & $40(35-45)$ & $39(33-42)$ & $39(35-43)$ & 0.003 & $<0.001$ \\
\hline 72 & $50(45-58)$ & $42(38-45)$ & $47(40-50)$ & $42(37-46)$ & $44(39-49)$ & $<0.001$ & $<0.001$ \\
\hline
\end{tabular}

Data are expressed as Median (Interquartile Range). ${ }^{a}$ p Values for between group comparisons were calculated using Kruskall Wallis Analyses; ${ }^{\mathrm{b}} \mathrm{p}$ Values for comparing the entire group to the actual value were calculated using the one-sample t-test. BMI: Body mass index; Endos: Endocrinologists; GPs: General Practitioners; Physios: Physiotherapists.

(b)

\begin{tabular}{ccccccc}
\hline \multirow{2}{*}{$\begin{array}{c}\text { Actual } \\
\text { BMI }\left(\mathrm{kg} / \mathrm{m}^{2}\right)\end{array}$} & \multicolumn{5}{c}{ Proportion that Recognised the Correct Obesity Class (\%) } \\
\cline { 2 - 6 } & Endos ( $=21)$ & GPs $(\mathrm{n}=96)$ & Diets $(\mathrm{n}=50)$ & Physios (n= 39) & All (n= 206) & $\mathrm{p}$ Value \\
\hline 32 & $71.4(15)$ & $44.3(43)$ & $36.0(18)$ & $21.1(8)$ & $40.8(84)$ & 0.002 \\
40 & $42.9(9)$ & $14.6(14)$ & $12.0(6)$ & $7.5(3)$ & $15.5(32)$ & 0.002 \\
51 & $61.9(13)$ & $50.0(48)$ & $62.0(31)$ & $47.5(19)$ & $53.6(111)$ & 0.376 \\
52 & $81.0(17)$ & $35.4(34)$ & $56.0(28)$ & $48.7(19)$ & $47.6(98)$ & 0.001 \\
72 & $95.2(20)$ & $71.9(69)$ & $78.0(39)$ & $66.7(26)$ & $74.8(154)$ & 0.081 \\
\hline
\end{tabular}

Data are expressed as Percentage (Number); p Values were calculated using Chi Square Analyses; For BMI 32 kg/m², proportion estimating a BMI > $30 \mathrm{~kg} / \mathrm{m}^{2}$ are shown; For BMI of $40 \mathrm{~kg} / \mathrm{m}^{2}$, proportion estimating a BMI $>35 \mathrm{~kg} / \mathrm{m}^{2}$ are shown; For the remaining BMIs $\left(51 \mathrm{~kg} / \mathrm{m}^{2}, 52 \mathrm{~kg} / \mathrm{m}^{2}, 72 \mathrm{~kg} / \mathrm{m}^{2}\right)$, proportion estimating a BMI $>40$ kg/m² are shown. BMI: Body mass index; Endos: Endocrinologists; GPs: General Practitioners; Diets: Dietitians; Physios: Physiotherapists.

data collection period.

During the data collection period weight was recorded for $18.1 \%(n=75)$ of patients (Table 2). Height was rarely measured $(1.0 \%(n=4))$ and no patient had BMI or waist circumference recorded (Table 2). All clinics had weighing scales with annual calibration and all but one had stadiometers. The majority of the clinics (76.9\% $[\mathrm{n}=20])$ had a measuring tape and two of them had a BMI chart.

Only ten of the 26 medical clinics surveyed weighed patients during the data collection period. Patients attending these ten clinics had an $11.8 \%$ to $88.9 \%$ chance of being weighed (Figure 2(a)). Eight percent $(n=6)$ of patients newly presenting to the clinics were weighed in contrast to $20.3 \%(n=69)$ of the returning patients. The sixteen clinics that did not measure patient weight included psychiatry clinics, specialty medical clinics (cardiology, respiratory, oncology and rheumatology) and surgical clinics (gastrointestinal, orthopaedic, urology, otolaryngology and gynaecology).

During the year preceding (and including) the data collection period, 33.4\% $(\mathrm{n}=172)$ and $4.3 \%(\mathrm{n}=22)$ of
Table 2. Proportion (\%) of healthcare records which had anthropometric measurements recorded.

\begin{tabular}{ccc}
\hline \multirow{2}{*}{ Measurement } & $\begin{array}{c}\text { Proportion (\%) of Healthcare Records with } \\
\text { Measurements Recorded }\end{array}$ \\
\cline { 2 - 3 } & $\begin{array}{c}\text { During Visit } \\
(\mathrm{n}=415)\end{array}$ & $\begin{array}{c}\text { During Preceding Year } \\
(\mathrm{n}=515)^{\mathrm{a}}\end{array}$ \\
\hline Weight & $18.1(75)$ & $33.4(172)$ \\
Height & $1.0(4)$ & $4.3(22)$ \\
Waist Circumference & $0(0)$ & $1.4(7)$ \\
Body Mass Index & $0(0)$ & $0.4(2)$ \\
\hline
\end{tabular}

Data are expressed as Percentage (number); ${ }^{a}$ Includes measurements made during clinic visit; 100 patients did not attend their scheduled appointments during the data collection period.

patients had their weight and height recorded (Table 2). Older patients were more likely to have been weighed ( $\mathrm{p}$ $=0.011)$. Women tended to be weighed more often than men $(36.5 \%$ versus $30.6 \%$, $\mathrm{p}=0.160)$. The likelihood of being weighed increased with increasing healthcare record thickness (Figure 2(b)). 


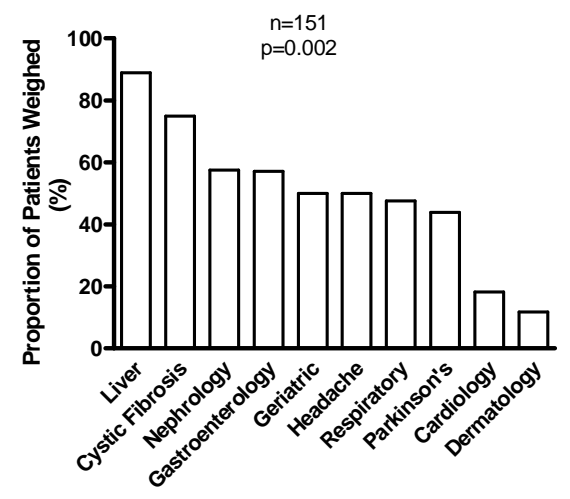

(a)

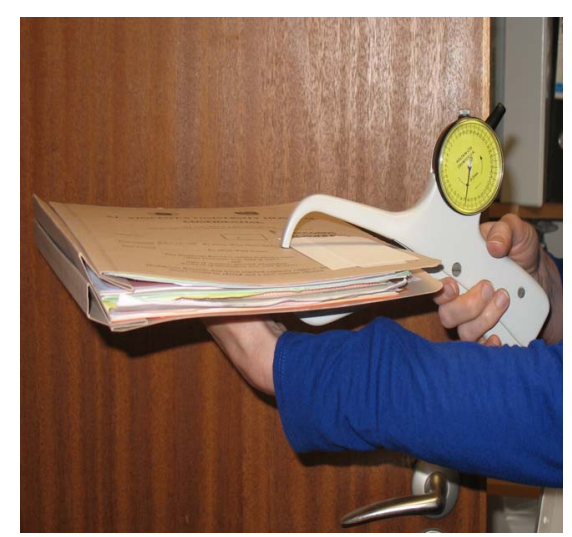

(b)

Figure 2. (a) Proportion (\%) of patients weighed during their outpatient clinic visit; (b) Chart thickness measurement by calipers.

\section{DISCUSSION}

Our study adds to the current literature by showing that not only do physicians under-recognise obesity and severe obesity, but so also do other HCPs. In addition to poorly estimating BMI by visual inspection (of photographs), HCPs do not routinely record weight or height. Fewer than $45 \%$ of HCPs recognised that a person with a BMI of $32 \mathrm{~kg} / \mathrm{m}^{2}$ was obese and fewer than $50 \%$ of HCPs recognised that a person with a BMI of $52 \mathrm{~kg} / \mathrm{m}^{2}$ was severely obese. Weight was recorded for fewer than $20 \%$ of patients attending hospital medical clinics. The gathered data suggest that endocrinologists were best at estimating BMI in the obese and in the severely obese, perhaps reflecting greater contact with obese individuals.

The association between healthcare record thickness and the probability of being weighed at a medical clinic is a novel finding. It could suggest an acknowledgement by patients or HCPs of the value of frequent weight checks for patients with multiple illnesses. Alternatively, it may reflect a desire by patients who seek the care of multiple HCPs to be regularly weighed. Equally, the possibility that the finding is a statistical aberration can- not be excluded.

Our findings are in keeping with those of the existing literature. Hendershot et al. compared the measured weights and heights of 110 trauma patients to the values estimated by HCPs and found that just $21 \%$ of treating physicians and nurses correctly recognised obese patients as having a BMI greater than $30 \mathrm{~kg} / \mathrm{m}^{2}$ [18]. Melamed et al. determined that no more than $24.4 \%$ of obese patients were diagnosed with obesity by their family physicians [19]. Melamed et al. also noted that just 35.3\% of patients had their BMI documented by their family physicians. Lopez-Jimenez et al. observed that only $14 \%$ of patients treated for acute myocardial infarction had their BMI documented in their healthcare records although weight and height were recorded in $98.9 \%$ and $97.8 \%$ of these patients respectively [20].

One of the limitations of the study is that the results may not be generalisable to HCPs dealing with other racial or ethnic groups because all the photographs used were of white people. Another limitation is that we used photographs as a proxy for visual inspection-we did not ask HCPs to directly estimate body mass index. We contend, however, that this is unlikely to explain obesity under-recognition-in our study $44 \%$ of family physicians recognised obesity in a patient with a BMI of 32 $\mathrm{kg} / \mathrm{m}^{2}$ which is much greater than an actual obesity recognition rate of $24.4 \%$ by family physicians [19]. An additional study shortcoming is that for some of the HCP groups the questionnaire was sent, in printed format, to individual HCPs whereas for other HCP groups the questionnaire was presented, in Powerpoint ${ }^{\circledR}$ format, to groups of HCPs. The poor response rate to the postal survey $(10.6 \%-46.0 \%)$ is a further drawback to this endeavour. It is likely, however, that the selection bias produced by this response rate is in favour of more accurate BMI estimations as the respondents may represent the HCPs who are more confident of their BMI estimation ability.

We conclude that appropriate therapy may not be offered to the obese or to the severely obese due to a lack of accurate diagnosis of their condition. Obesity is a risk factor for a wide range of chronic illnesses and can worsen disease severity and can adversely affect treatment outcomes [21-28]. Conversely obesity management can improve outcomes for multiple diseases [24-26,29]. Our findings reinforce the need for all HCP-patient encounters to involve routine measurement of weight and height.

\section{ACKNOWLEDGEMENTS}

This work was not supported by any grants or fellowships. Cecily Kelleher and Donal O'Shea are co-investigators in the Irish Health Research Board funded Centre for Food and Health which has a special 
interest in determinants of obesity.

\section{REFERENCES}

[1] Flegal, K.M., Carroll, M.D., Kuczmarski, R.J. and Johnson, C.L. (1998) Overweight and obesity in the United States: Prevalence and trends, 1960-1994. International Journal of Obesity, 22, 39-47. doi:10.1038/sj.ijo.0800541

[2] Ogden, C.L., Carroll, M.D., Curtin, L.R., McDowell, M.A., Tabak, C.J. and Flegal, K.M. (2006) Prevalence of overweight and obesity in the United States, 1999-2004. Journal of the American Medical Association, 295, 15491555. doi:10.1001/jama.295.13.1549

[3] The Health and Social Care Information Centre (2009) Health Survey for England 2008. The NHS Information Centre for Health and Social Care, Leeds.

[4] Popkin, B.M. (2010) Recent dynamics suggest selected countries catching up to US obesity. American Journal of Clinical Nutrition, 91, 284S-288S. doi:10.3945/ajen.2009.28473C

[5] Garcia-Alvarez, A., Serra-Majem, L., Ribas-Barba, L., Castell, C., Foz, M., Uauy, R., et al. (2007) Obesity and overweight trends in Catalonia, Spain (1992-2003): Gender and socio-economic determinants. Public Health $\mathrm{Nu}$ trition, 10, 1368-1378. doi:10.1017/S1368980007000973

[6] Basterra-Gortari, F.J., Beunza, J.J., Bes-Rastrollo, M., Toledo, E., Garcia-Lopez, M. and Martinez-Gonzalez, M.A. (2011) Increasing trend in the prevalence of morbid obesity in Spain: From 1.8 to 6.1 per thousand in 14 years. Revista Española de Cardiología, 64, 424-426. doi:10.1016/j.recesp.2010.06.010

[7] Sturm, R. (2007) Increases in morbid obesity in the USA: 2000-2005. Public Health, 121, 492-496. doi:10.1016/j.puhe.2007.01.006

[8] McGee, D.L. (2005) Body mass index and mortality: A meta-analysis based on person-level data from twenty-six observational studies. Annals of Epidemiology, 15, 87-97. doi:10.1016/j.annepidem.2004.05.012

[9] Gregg, E.W., Gerzoff, R.B., Thompson, T.J. and Williamson, D.F. (2003) Intentional weight loss and death in overweight and obese US adults 35 years of age and older. Annals of Internal Medicine, 138, 383-389.

[10] Sjostrom, L., Narbro, K., Sjostrom, C.D., Karason, K., Larsson, B., Wedel, H., et al. (2007) Effects of bariatric surgery on mortality in Swedish obese subjects. New England Journal of Medicine, 357, 741-752. doi:10.1056/NEJMoa066254

[11] Adams, T.D., Gress, R.E., Smith, S.C., Halverson, R.C., Simper, S.C., Rosamond, W.D., et al. (2007) Long-term mortality after gastric bypass surgery. New England Journal of Medicine, 357, 753-761. doi:10.1056/NEJMoa066603

[12] McArtor, R.E., Iverson, D.C., Benken, D. and Dennis, L.K. (1992) Family practice residents' identification and management of obesity. International Journal of Obesity and Related Metabolic Disorders, 16, 335-340.

[13] Bardia, A., Holtan, S.G., Slezak, J.M. and Thompson,
W.G. (2007) Diagnosis of obesity by primary care physicians and impact on obesity management. Mayo Clinic Proceedings, 82, 927-932. doi:10.4065/82.8.927

[14] Logue, E., Gilchrist, V., Bourguet, C. and Bartos, P. (1993) Recognition and management of obesity in a family practice setting. Journal of the American Board of Family Practice, 6, 457-463.

[15] Bramlage, P., Wittchen, H.U., Pittrow, D., Kirch, W., Krause, P., Lehnert, H., et al. (2004) Recognition and management of overweight and obesity in primary care in Germany. International Journal of Obesity and Related Metabolic Disorders, 28, 1299-1308. doi:10.1038/sj.ijo.0802752

[16] Ruser, C.B., Sanders, L., Brescia, G.R., Talbot, M., Hartman, K., Vivieros, K., et al. (2005) Identification and management of overweight and obesity by internal medicine residents. Journal of General Internal Medicine, 20, 1139-1141. doi:10.1111/j.1525-1497.2005.0263.x

[17] Polednak, A.P. (2009) Recognition of comorbid diabetes and obesity in hospital records of newly diagnosed cancer patients. Annals of Oncology, 20, 591-592. doi:10.1093/annonc/mdn754

[18] Hendershot, K.M., Robinson, L., Roland, J., Vaziri, K., Rizzo, A.G. and Fakhry, S.M. (2006) Estimated height, weight, and body mass index: Implications for research and patient safety. Journal of the American College of Surgeons, 203, 887-893. doi:10.1016/j.jamcollsurg.2006.08.018

[19] Melamed, O.C., Nakar, S. and Vinker, S. (2009) Suboptimal identification of obesity by family physicians. American Journal of Managed Care, 15, 619-624.

[20] Lopez-Jimenez, F., Malinski, M., Gutt, M., Sierra-Johnson, J., Aude, Y.W., Rimawi, A.A., et al. (2005) Recognition, diagnosis and management of obesity after myocardial infarction. International Journal of Obesity, 29, 137-141. doi:10.1038/sj.ijo.0802831

[21] Setty, A.R., Curhan, G. and Choi, H.K. (2007) Obesity, waist circumference, weight change, and the risk of psoriasis in women: Nurses' health study II. Archives of Internal Medicine, 167, 1670-1675. doi:10.1001/archinte.167.15.1670

[22] Bardazzi, F., Balestri, R., Baldi, E., Antonucci, A., De Tommaso, S. and Patrizi, A. (2010) Correlation between BMI and PASI in patients affected by moderate to severe psoriasis undergoing biological therapy. Dermatology and Therapy, 23, S14-S19. doi:10.1111/j.1529-8019.2009.01281.x

[23] Naldi, L., Addis, A., Chimenti, S., Giannetti, A., Picardo, M., Tomino, C., et al. (2008) Impact of body mass index and obesity on clinical response to systemic treatment for psoriasis. Evidence from the Psocare project. Dermatology, 217, 365-373. doi:10.1159/000156599

[24] Romero-Corral, A., Caples, S.M., Lopez-Jimenez, F. and Somers, V.K. (2010) Interactions between obesity and obstructive sleep apnea: Implications for treatment. Chest, 137, 711-719. doi:10.1378/chest.09-0360

[25] Bigal, M.E. and Rapoport, A.M. (2011) Obesity and chronic daily headache. Current Pain and Headache Reports, 12, 56-61. doi:10.1007/s11916-008-0011-8 
[26] Adams, T.D. and Hunt, S.C. (2009) Cancer and obesity: Effect of bariatric surgery. World Journal of Surgery, 33, 2028-2033. doi:10.1007/s00268-009-0169-1

[27] Parekh, N., Okada, T. and Lu-Yao, G.L. (2009) Obesity, insulin resistance, and cancer prognosis: Implications for practice for providing care among cancer survivors. Journal of the American Dietetic Association, 109, 1346-1353. doi:10.1016/j.jada.2009.05.001

[28] McWilliams, R.R., Matsumoto, M.E., Burch, P.A., Kim, G.P., Halfdanarson, T.R., de Andrade, M., et al. (2010)
Obesity adversely affects survival in pancreatic cancer patients. Cancer, 116, 5054-5062. doi:10.1002/cncr.25465

[29] Gisondi, P., Del Giglio, M., Di Francesco, V., Zamboni, M. and Girolomoni, G. (2008) Weight loss improves the response of obese patients with moderate-to-severe chronic plaque psoriasis to low-dose cyclosporine therapy: A randomized, controlled, investigator-blinded clinical trial. American Journal of Clinical Nutrition, 88, 1242-1247. 